\title{
Local Kinetic Architecture to develop Egypt's Housing spaces
}

\author{
Mohamed Hassan Atwa Eldek*, Faysal Abo-Elazm ${ }^{* *}$, Yara El-sayed Emara ${ }^{* *}$ \\ * Professor at Department of architecture, design, and urban planning, Faculty of Engineering, Suez Canal University, Ismailia, Egypt \\ *** professor at Department of Architecture and Urban Planning, Faculty of Engineering, Suez Canal University, Ismailia, Egypt \\ ** Demonstrator at Department of Architecture and Urban Planning, Faculty of Engineering, Suez Canal University, Ismailia, Egypt.
}

DOI: 10.29322/IJSRP.11.11.2021.p11913

http://dx.doi.org/10.29322/IJSRP.11.11.2021.p11913

\begin{abstract}
As the world evolves and changes, the requirements and needs of users in buildings change, and thus the needs of the population in Egypt are changing, so it has become necessary to resort to innovative solutions that keep pace with the times, and one of the most important features of kinetic architecture is that it keeps pace with development and is flexible in use, and therefore it is the best solution Architectural problems in this era.

The paper discusses an approach to develop housing in Egypt through kinetic architecture with local tools, to meet the changing needs of the population, among these needs, physical needs such as the desire to increase the housing area, or change the vision, or provide light, thermal and air comfort in different seasons, and the needs of users may be non-physical, such as the desire to change and try something new for the dwelling, or to show off, so kinetic architecture works to provide different solutions to meet these changing needs to keep pace with the permanent changes faced by contemporary society, Where kinetic architecture can be used to enhance the aesthetic characteristics of the building or to interact with environmental conditions or Implementation of functions that are difficult to achieve fixed construction.

In this paper A proposed unit is presented as one of the solutions which users can be provided with additional space that can be used according to their needs, using the kinetic architecture.
\end{abstract}

Index Terms- Local Kinetic Architecture, Mechanism, Motion, Housing, Extra space

\section{INTRODUCTION}

$I^{n}$ $\mathrm{n}$ recent years, a trend has emerged that calls for looking at the building as a structure in a state of dynamic equilibrium and not as a traditional structure in static equilibrium. And how to change the course of human life and make it shorten the time and effort in the buildings in which the person lives and exercises his life functions.

The rapid development in various social, economic, and technological fields is changing the lifestyle, behaviors, habits, and daily needs of people at the same rate. Accordingly, our expectations are constantly changing from the spaces in which we carry out various activities. As the buildings are initially designed for specific purposes and needs do not provide the expected functionality after a while with the continuous changes of users' requirements. With the flexibility available in architectural design, buildings must be transformable and changeable after the design is completed

\section{KINETIC ARCHITECTURE}

Kinetic architecture is a product of the development of architecture through the ages, where architecture is transferred from a fixed form to a moving one and the transition from boredom and monotony to vitality and change. Buildings go back to ancient times and were represented in the movement of doors and windows and the movement of bridges in castles and fortresses that were used for defensive purposes, then witnessed a great development with time, from manual systems to mechanical and then to electronic and smart systems and became more and more diverse in use.

The main reason for building any architectural facility is to achieve the goal of the users and meet their physical and non-physical needs, and thus the architectural spaces of this facility become successful. kinetic architecture provides solutions and ideas that can keep pace with the constantly changing needs of users.

\section{A. Kinetic Architecture objectives}

kinetic architecture must meet the needs of the user in perceiving the pleasure and savoring the formal beauty as well as the function. The intended use of movement in architecture varies according to usual conditions and requirements. As the main motive for the trend towards kinetic architecture is the need for comfort, flexibility and the ability to change the shape, and the uses of kinetic architecture can be classified into functional, formative, environmental and economic uses fig(1). 
The functional objectives divide into Flexibility in achieving various functions which depend on equipping spaces with mechanisms that allow spaces to be transformed into a limited number of spatial variations to serve a specific number of tasks, Harmony with Environment as There are times when people benefit from or avoid nature such as climate change, daily weather conditions, sun, wind, Location change \& various views due to the need to change the location in the building[1], Space increasing as The expandable, shrinkable, open and closed surfaces are designed to increase the versatility of spaces, so space shapes can be changed to suit different functions[2]. Formative objectives as One of the most important effects that the movement achieves for construction while gaining a new dimension through the architectural movement is to change the aesthetic perception and create a mind-blowing appearance for the users. Where changing kinetic shapes and structural formations leads to different feelings for people. Economic objectives that kinetic buildings could reduce energy waste by using kinetic elements allow the building to be adapted with the weather, also kinetic buildings could be a landmark attract income [3].
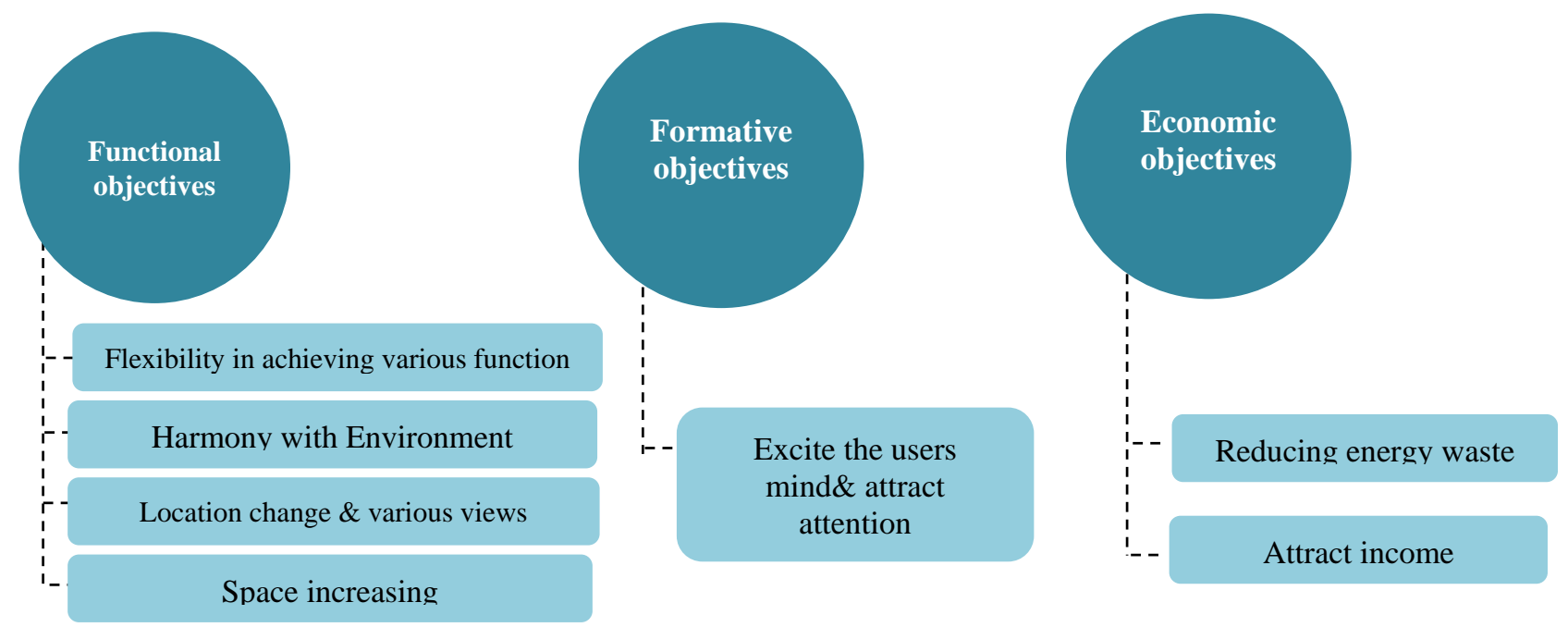

Figure 1 objectives of kinetic architecture, source: the researcher

\section{HOUSING \& USERS RESPONSES}

It is the shelter that includes the individual and the family and the nucleus of stability in its comprehensive sense, which is a prerequisite for human giving in its sensory and intellectual dimensions. Hence the importance and value of housing for the individual and society. [4] Also, it is the place where a person satisfies a large part of his physical, non-physical needs and it's a source of health safety.[5]the dwelling is also the container that expresses the degree of transformation in the personality of the one who inhabits it.[6]

\section{A. Behavioral responses of housing spaces users}

\section{First: human behavior}

It is the adaptation between an individual and his environment.[7] also, It is any action by which a living organism responds to a situation and the response depends on its previous experiences.[8]

As behind every human behavior is a motive, and behind every motive is a desire, and the motive refers to an internal state that results from a need, and this state activates the behavior towards achieving the desired need.

\section{Second: the response of users to the design of architectural spaces}

The response of users to the design of architectural spaces varies, and it is divided into three categories [9] as shown fig 2:

- Give up to the space and interact with it.

- Attempting to modify the space to suit the needs of the population.

- Not interacting with the space and the abandonment of users to it.

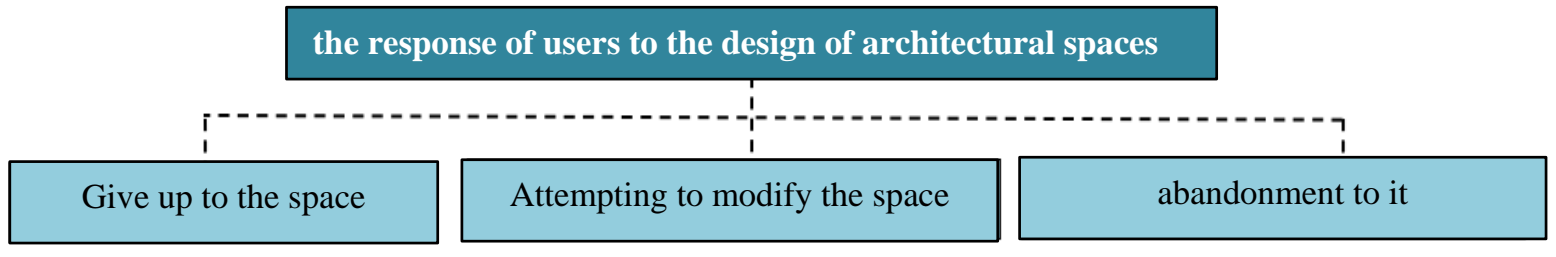

Figure 2 the response of users to the design of architectural spaces, source: the researcher

From here, the designer had a great role in understanding the human needs within the space, and how the person accommodates the formations of the surrounding residential spaces that should meet the purpose assigned to them [10]. 


\section{THE KINETIC PROPOSED DESIGN}

\section{A. Design concept for proposed unit}

Through the kinetic architecture, the room is provided with an additional area of up to $6 \mathrm{~m} 2$ that allows the user to use it according to the needs to be achieved.

- The dimensions of the original room is $(3 \mathrm{~m} * 4 \mathrm{~m})$

- Dimensions of the additional space provided by the mobile model is $(2 \mathrm{~m} * 3 \mathrm{~m})$ fig (3)
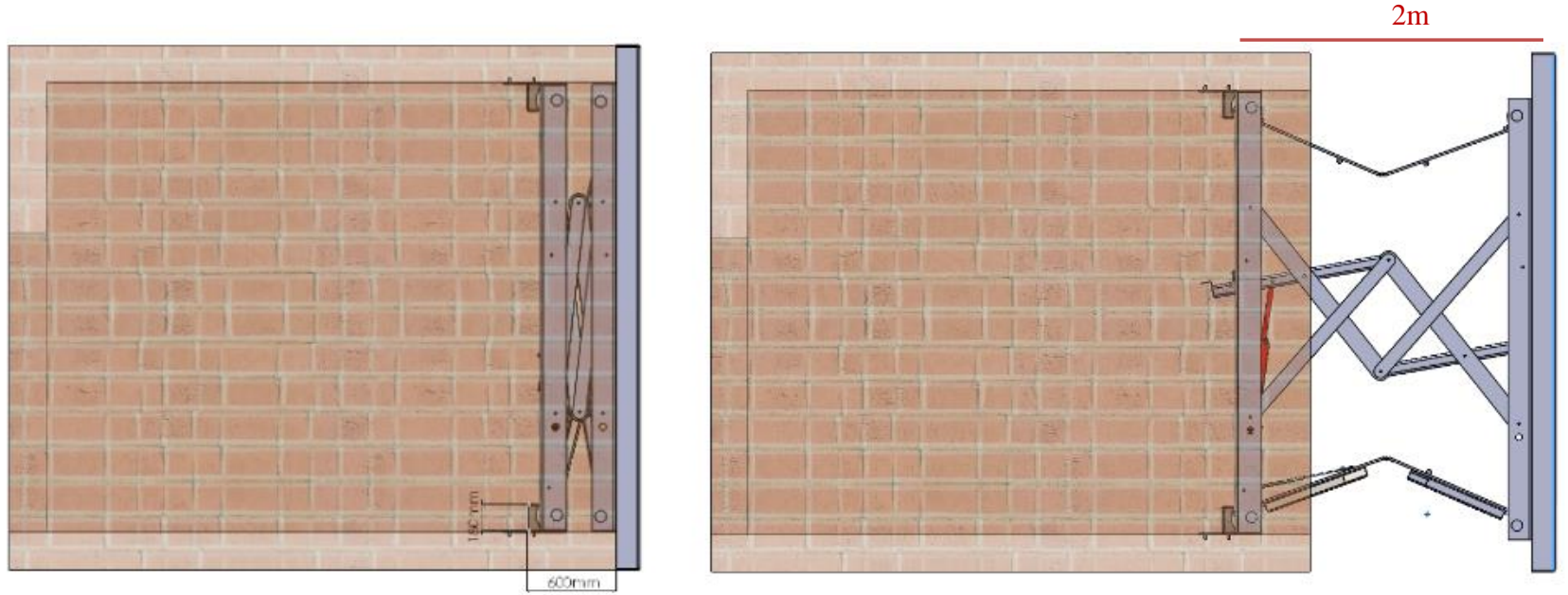

Figure 3 proposed kinetic design of extension $2 \mathrm{~m}$ length , $3 \mathrm{~m}$ width, source: the researcher

The additional space could be used by the users as a terrace or, for adding extra bed to the room or, for a certain activity fig (4)
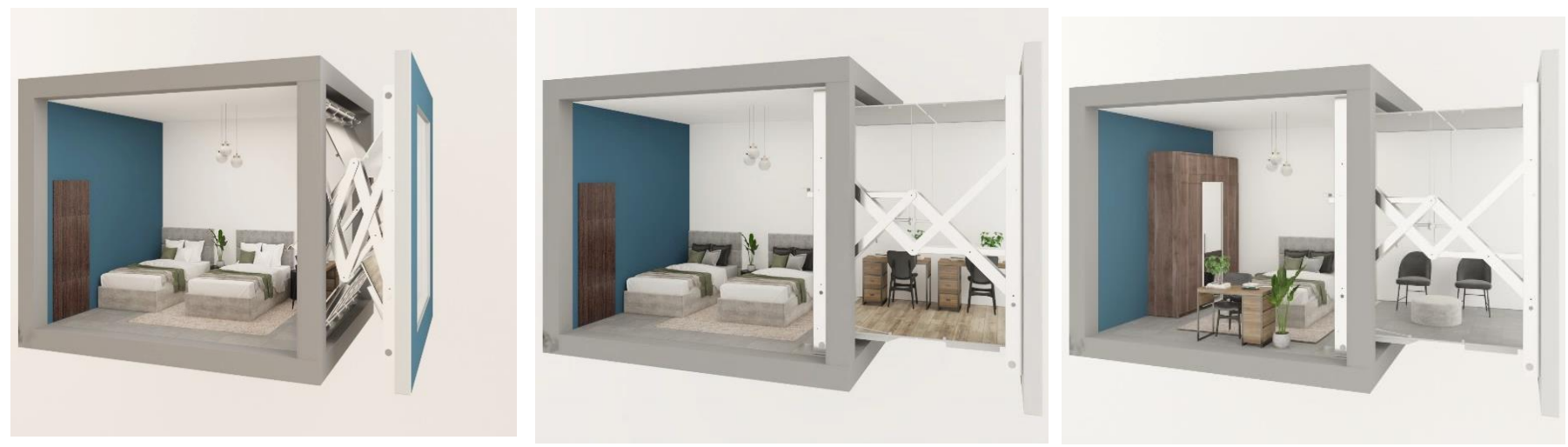

Figure 4 different uses for the kinetic space, source: the researcher

\section{B. Formation concept for proposed unit}

The unit gives an aesthetic shape to the external facade, giving a diversity and difference to the facades when using more than one unit, but in an organized and designed way. Where it is possible to install more than one unit for the building and paint the units in consistent colors, which gives and attracts attention to residential buildings in Egypt.


Figure 5 expected façade by using the kinetic model, source: the researcher 


\section{Structure of the proposed unit}

The unit consists of a foldable system consisting of three basic connecting parts, and a steel base, working to provide an open and closed space as in the shape.


6 Proposed mechanism of the kinetic model, source: the researcher

Figure

- The total mechanism weighs about 5 tons therefore, the room must withstand this additional load.

- The load on which the loads were calculated is $450 \mathrm{~kg}$ per square meter, according to the calculations of live and dead loads.

Structural components can be determined to fail by various modes determined by buckling, deflection, natural frequency, strain, or stress. Strain or stress failure criteria are different depending on whether they are considered as brittle or ductile materials. The difference between brittle and ductile material behaviors is determined by their response to the loads fig (7).

Here, a Von Mises stress energy failure theory is used to test our material and to detect the possible deflection that can be occurred due to the applied load using SOLIDWORKS software. AISI 304 is the main material of the various parts of the mechanism which its yield strength is about $2.068 \times 10^{8}$.

The following figures will indicate the stress analysis and the deformation on the different parts of the mechanism. The total mechanism approximately weights 5 ton so, the room must sustain this additional load.

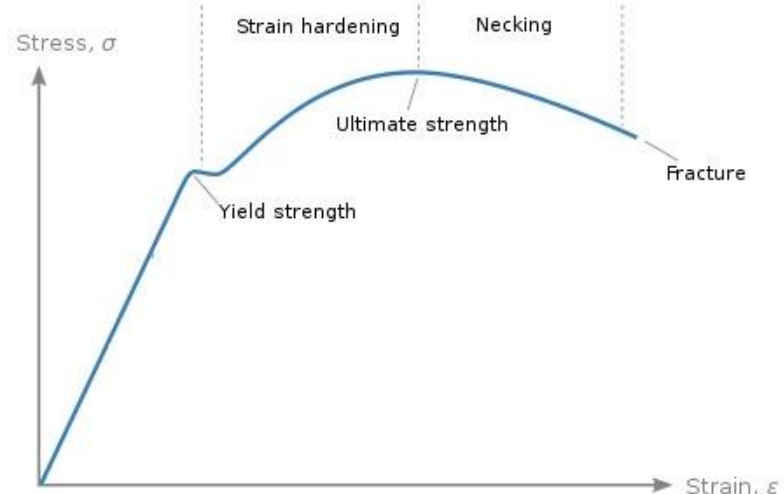

Figure 7 the phases of the reaction of a (Mild steel) starting from the flexibility stage, then plastic, then the hard strain, stage where the increase in the resistance of the material and then the stage of collapse, source: Courtney, Thomas (2005). Mechanical behavior of materials.








This publication is licensed under Creative Commons Attribution CC BY. 


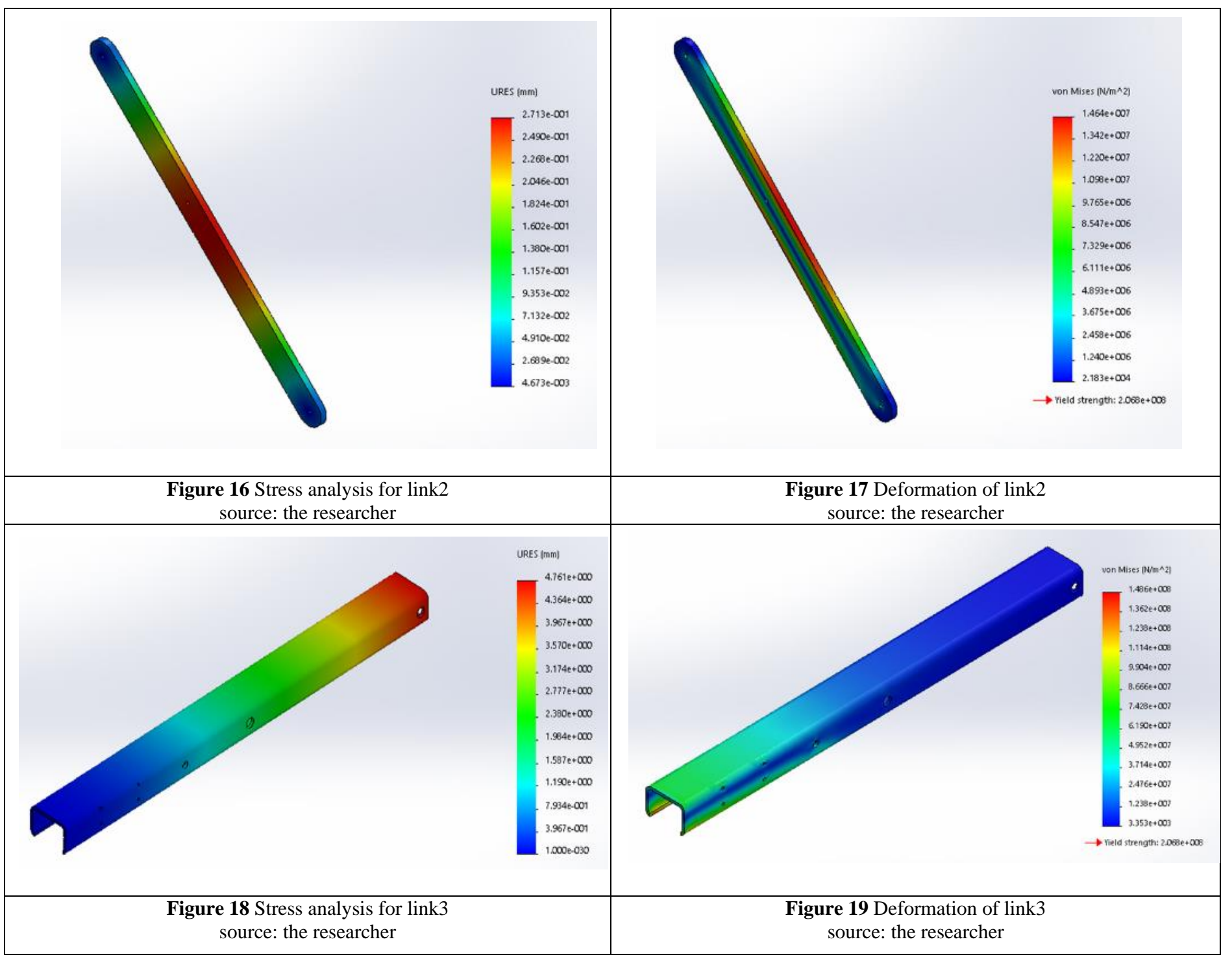

\section{Automation Technology of proposed unit Working Theory}

- This mechanism operates manually when the user moves the hand of the pump down, it gradually pushes link3 up, then all the mechanism opens to 2 meters as shown fig (20).

- To close the mechanism all the user should do is to rotate the release button of the pump, the mechanism will return back to the closed state.

- This mechanism consists of three main categories

Which are: source of movement, movement supporters, Movable body.

- First category is source of movement in the mechanism is the pump which provide the main motion, second the movement supporters consist of Lift supports, radial ball bearing, Hinges, Latch. last category is the movable body which contain the links, base, ceiling, and elevation as shown fig (21).

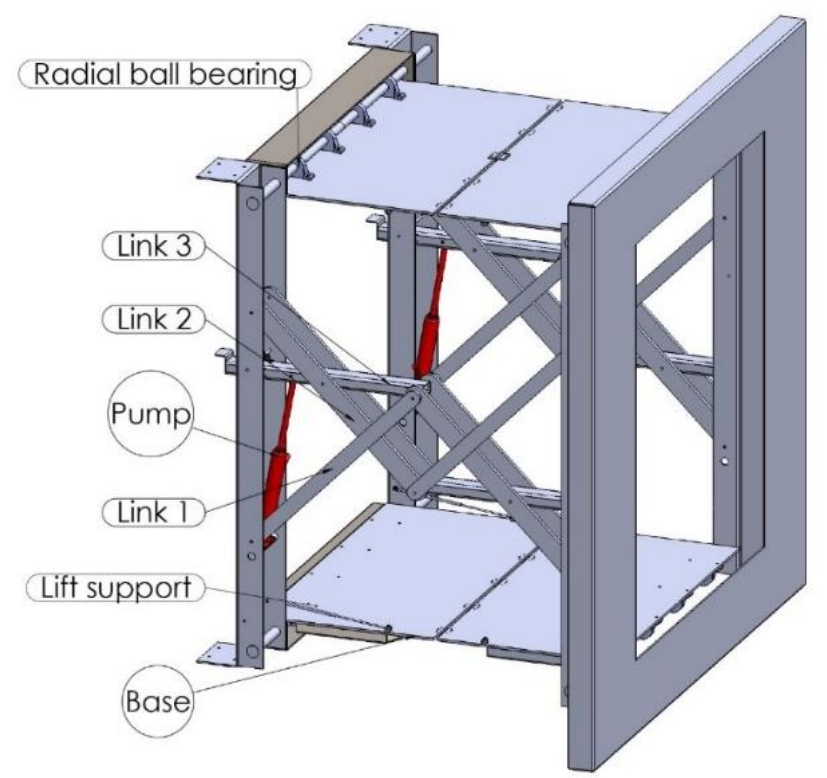

Figure 20 Elements of the kinetic mechanism source: the researcher 




Figure21 kinetic unit components, source: the researcher

As shown in Table 1 components of the proposed mechanism and its function, description, and quantity needed of each component.



Table 1 kinetic unit components specification, source: the researcher 


\section{IMPACT ON MAIN ARCHITECTURAL WORK}

Every architectural work has an impact on the main aspects of architecture, whether it is a functional aspect, formative, structural, technological aspect. the shown Table 2 represents the points that the proposed mechanism has an impact on it in the four main aspects of architectural work.

\begin{tabular}{|c|c|c|c|c|c|}
\hline \multicolumn{6}{|c|}{ Impact of the kinetic model on architectural work aspects } \\
\hline \multirow{20}{*}{  } & \multicolumn{2}{|c|}{ Architectural work aspects } & Description & Achieve & Not achieved \\
\hline & \multirow{6}{*}{$\begin{array}{l}\text { Functional } \\
\text { aspect }\end{array}$} & lighting & $\begin{array}{l}\text { The appropriate distribution of lighting, weather it is } \\
\text { natural or artificial lighting, and it is preferable to be } \\
\text { natural. }\end{array}$ & $\checkmark$ & \\
\hline & & $\begin{array}{l}\text { Thermal comfort \& } \\
\text { ventilation }\end{array}$ & $\begin{array}{l}\text { Providing the necessary ventilation through the use } \\
\text { of openings and the ability of the space to adapt to } \\
\text { the seasons of the year. }\end{array}$ & $\checkmark$ & \\
\hline & & privacy & $\begin{array}{l}\text { The possibility of controlling the opening or closing } \\
\text { of the building in relation to the outside. }\end{array}$ & $\checkmark$ & \\
\hline & & Security\& safety & $\begin{array}{l}\text { The use of security and safety factors in the building } \\
\text { and thus achieve safety }\end{array}$ & $\checkmark$ & \\
\hline & & $\begin{array}{l}\text { Flexibility in achieving } \\
\text { various function }\end{array}$ & $\begin{array}{l}\text { Flexibility of space to adapt to the functions to be } \\
\text { achieved according to the users. }\end{array}$ & $\sqrt{ }$ & \\
\hline & & $\begin{array}{l}\text { Change of views/ spatial } \\
\text { diversity }\end{array}$ & $\begin{array}{l}\text { Providing various viewing angles for the building } \\
\text { without moving it. }\end{array}$ & $\sqrt{ }$ & \\
\hline & \multirow{6}{*}{$\begin{array}{l}\text { Formative } \\
\text { aspect }\end{array}$} & $\begin{array}{l}\text { Harmony with physical } \\
\text { Environment }\end{array}$ & $\begin{array}{l}\text { The shape of the building matches the surrounding } \\
\text { environment. }\end{array}$ & & $\checkmark$ \\
\hline & & Rhythm & $\begin{array}{l}\text { Consisting of repeating masses, shapes, colors, or } \\
\text { levels. }\end{array}$ & $\checkmark$ & \\
\hline & & proportion Harmonious & $\begin{array}{l}\text { Compatibility and harmony between the mass and } \\
\text { some of it, as well as between the mass and its } \\
\text { surroundings and its components. }\end{array}$ & & $\checkmark$ \\
\hline & & openings & The ratio of openings and solids in blocks. & $\sqrt{ }$ & \\
\hline & & Light \& Shade & $\begin{array}{l}\text { It results from forming masses, shapes, colors or } \\
\text { levels. }\end{array}$ & $\sqrt{ }$ & \\
\hline & & Diversity & $\begin{array}{l}\text { Diversity in the use of blocks and shapes together to } \\
\text { make a formation that attracts attention. }\end{array}$ & $\sqrt{ }$ & \\
\hline & \multirow{3}{*}{$\begin{array}{l}\text { Structural } \\
\text { aspect }\end{array}$} & Stability & $\begin{array}{l}\text { The use of a structural system that achieves stability } \\
\text { and balance for the building }\end{array}$ & $\checkmark$ & \\
\hline & & Efficiency of materials & $\begin{array}{l}\text { Use efficient materials to achieve the structural } \\
\text { system. }\end{array}$ & $\checkmark$ & \\
\hline & & $\begin{array}{l}\text { Economic efficiency of } \\
\text { the construction system }\end{array}$ & $\begin{array}{l}\text { Provide the amount of material in the structural } \\
\text { system. }\end{array}$ & $\checkmark$ & \\
\hline & \multirow{4}{*}{$\begin{array}{l}\text { Technology } \\
\text { aspect }\end{array}$} & Control mechanisms & $\begin{array}{l}\text { Evolution of the methods and control methods used } \\
\text { in the building. }\end{array}$ & $\sqrt{ }$ & \\
\hline & & $\begin{array}{l}\text { Development of } \\
\text { implementation Methods }\end{array}$ & $\begin{array}{l}\text { The development of mechanisms and methods of } \\
\text { implementation and construction through } \\
\text { technology. }\end{array}$ & $\sqrt{ }$ & \\
\hline & & $\begin{array}{l}\text { Structural analysis } \\
\text { \&design techniques }\end{array}$ & $\begin{array}{l}\text { The use of computer programs during the design and } \\
\text { structural analysis process. }\end{array}$ & $\sqrt{ }$ & \\
\hline & & $\begin{array}{l}\text { Evolution of material } \\
\text { technology }\end{array}$ & Using innovative smart materials in the building. & & \\
\hline
\end{tabular}


Table 2 Impact of the kinetic model on architectural work aspects, source: the researcher

\section{CONCLUSION}

The study adopts a developed method by kinetic architecture as an approach to fulfill user's needs by providing them with additional space, that can be used according to their changing needs, The proposed kinetic model provides the user with the right to control the additional space, whether by opening or closing it, according to his needs.

The kinetic model provides a different experience for users in the space. Using the proposed model Preserves the shape of the buildings when there is a need to add space without the need to close the balconies or distort the shape of buildings.

The kinetic model has an impact on many elements of the main aspects of architecture, as the possibility of controlling the opening or closing of the building in relation to the outside, which provide people to control lighting, Thermal comfort \& ventilation according people need. Also, the Diversity in the use of blocks and shapes together to make a formation that attracts attention.

\section{ACKNOWLEDGMENT}

I would like to Appreciate everyone helped in accomplishing this work, all my gratitude for your valuable support and guidance.

\section{REFERENCES}

[1] H. Ghamari, M. Asefi, "Toward Sustainability by the Application of Intelligence Building Systems". The Second International Conference on Sustainable Architecture and Urban Development, Jordan, 245-248, 2010

[2] Forty, A., Words and Buildings, Thames\& Hudson, London, 2000

[3] Zeynep Yeşim İLERİSOY, Merve PEKDEMIR BAŞEĞMEZ2, Conceptual Research of Movement in Kinetic Architecture Department of Architecture, Gazi University Journal of Science, Ankara, Turkey,2018

[4] Syed Bassiouni, Architecture art book, Yazouri Group for Publication and Distribution, 2017

[5] Hawalifa Boumediene, The health level of the population and the achievement of development, the role of municipalities in raising the Algerian, a working paper at a conference in Bahrain, March 26, 2006

[6] Mashari Abdullah Al-Naim, Human Spaces for Housing, Saudi Building Magazine, Riyadh, Kingdom of Saudi Arabia, Issue 162 February 2004

[7] Abdel Aziz Al-Qousi, Psychology: Its Foundations and Educational Applications, The Egyptian Renaissance Library, 1970

[8] Ahmed Magdy Hegazy, Transforming and Changing Values among Egyptian Youth - Study of the Crisis of Values, Fifth Annual Conference (Social Change in Egyptian Society during 50 Years), National Center for Social Research, 2003

[9] Laila Alaa El Din Jamil Ahmed, Design mechanisms and solutions for the development of slum dwellings, Faculty of Applied Arts - Helwan University,2017

[10] Dr. Kassab, Ahmed Saeed, Towards a Socially Effective Residential Environment in Contemporary Residential Architecture, Tishreen Journal of Research and Scientific Studies, Engineering Sciences Series, Volume 35, Issue 1, Syria, 2012

\section{AUTHORS}

First Author - Mohamed Hassan Atwa Eldek, prof.Dr, at Department of architecture, design, and urban planning, Suez Canal University, Ismailia, Egypt.

Second Author - Faysal Abo-Elazm, Professor at Department of Architecture and Urban Planning, Suez Canal University, Ismailia, Egypt.

Third Author - Yara Elsayed Emara , Demonstrator at Department of Architecture and Urban Planning, Faculty of Engineering, Suez Canal University, Ismailia, Egypt.

Correspondence Author - Yara Elsayed Emara, yara.emara@su.edu.eg, yara.emara11@gmail.com. 
